\title{
Modeling Impact of Hurricane Damages on Income Distribution in the Coastal U.S.
}

\author{
Tatjana Miljkovic $\cdot$ Dragan Miljkovic
}

Published online: 15 October 2014

(c) The Author(s) 2014. This article is published with open access at Springerlink.com

\begin{abstract}
This article examines the impact of catastrophic hurricane events on income distribution in hurricane states in the United States. Media claims have been made and the perception created that the most damaging impact of hurricanes is on the lowest income population in the affected states. If these claims are true, they may have serious implications for the insurance industry and government policy makers. We develop a panel data, fixed effects econometric model that includes hurricane-impacted states as cross-sections using annual data for a period of almost 100 years. The Gini coefficient is used as a measure of income inequality, and is a function of normalized hurricane economic damages, gross domestic product (GDP), a set of socioeconomic variables that serves as a control, time trend, and cross-sectional dummy variables. Findings indicate that for every 100 billion US dollars in hurricane economic damages there is an increase in income inequality by $5.4 \%$ as measured by Gini coefficient. Political, sociodemographic, and economic variables are also significant. These include such variables as the political party controlling the U.S. Senate, the proportion of nonwhite population by state, and GDP. Time trend is a positive and significant variable, suggesting an increase in income inequality over time. There are significant differences among the states included in the study. Our results demonstrate that different segments of the population are differently impacted by hurricanes and suggest how that
\end{abstract}

\section{T. Miljkovic}

Department of Statistics, North Dakota State University, Fargo,

ND 58108, USA

D. Miljkovic $(\square)$

Department of Applied Economics, North Dakota State

University, Fargo, ND 58108, USA

e-mail: dragan.miljkovic@ndsu.edu differential impact could be considered in future government policies and business decisions, particularly those made by the insurance industry.

Keywords Hurricane damages · Income distribution $\cdot$ Disaster insurance $\cdot$ United States

\section{Introduction}

The economics literature demonstrates that although richer nations do not experience fewer natural disasters than poorer nations, richer nations do suffer less death and longterm property damages from disaster (Kahn 2005; Toya and Skidmore 2007). Therefore economic development provides implicit insurance against nature's shocks. Nations with higher-quality and more robust institutions suffer less death and long-term property damages from natural disasters. A disproportionate share of the deaths caused by such environmental shocks as earthquakes, floods, cyclones, hurricanes, and extreme temperature events are borne by people in developing countries. The Intergovernmental Panel on Climate Change (Vellinga and Mills 2001) reports that $65 \%$ of world deaths from natural disasters between 1985 and 1999 took place in nations whose incomes were below USD 760 per capita. "Ninety percent of the disaster victims worldwide live in developing countries where poverty and population pressures force growing numbers of poor people to live in harm's way on flood plains, in earthquake prone zones and on unstable hillsides. Unsafe buildings compound the risks. The vulnerability of those living in risk prone areas is perhaps the single most important cause of disaster casualties and damage" (Annan 1999). Although this view is widely accepted as factual, there are some studies that indicate that 
behavioral changes at the micro level in response to increasing income (such as location choice and extent of costly abatement activity) may lead to a nonlinear relationship between aggregate incomes and disaster damages, where the risks increase with income before they decrease (Kellenberg and Mobarak 2008). The implication of this view is that in addition to allocating resources to manage disaster risk, the poorest nations may have to be more proactive in enacting policies that alter those behavioral choices of citizens that impact a country's exposure to natural disaster risk.

Similar issues are pertinent at the national level as well. If it is actually true that catastrophic events such as hurricanes further increase income inequality in affected areas, the consequences are very important not only for policy makers but also for insurance companies. Many low income families do not have any property (primarily home) insurance. If the impact burden of low income families increases following a catastrophe, the government will be pressured to provide both short- and long-term assistance to these families. Likewise, fewer low income families will be in position after a disaster to purchase insurance. This in turn will force premiums for both existing and future home insurance policy buyers to further increase as the short-run insurance industry supply curve of property insurance policies begins to slope steadily upward (Gronn 1994). Hence determining that hurricanes had (or alternatively did not have) an impact on income distribution in affected states during the last 100 years should provide some direction and enable the dialogue among all parties impacted by these events-federal and state government as a social planner, insurance companies as profit-oriented enterprises, and people living in these areas. Otherwise, the chances are that the conundrum of addressing the problems following future hurricane devastations will be resolved on an ad hoc basis, as has so often been the case in the past, thus furthering social divisions and increasing social tensions.

The question of interest in this article is: are relatively poorer people more likely to be impacted more severely by catastrophic events? More specifically, we ask: do catastrophic events such as hurricanes impact the income distribution in the affected states of the United States, and, if so, in what way? We are also interested in seeing if different regions (states) are impacted differentially by these catastrophic events, and, if they are, why that is the case. Strangely, although the United States experienced some of the most severe hurricanes during the last century, there are only a few studies that try to address this issue. Moreover, these studies are case studies examine the impact of a single catastrophic event (for example, hurricane) on the affected area (West and Lenze 1994; Masozera et al. 2007). As a more recent example, Masozera et al. (2007) examined whether neighborhoods in New Orleans were impacted differently by Hurricane Katrina based on preexisting social, physical, and economic vulnerabilities. They evaluate the degree to which the initial impacts of Hurricane Katrina were distributed among the New Orleans' residents. Their findings suggest that preexisting socioeconomic conditions play a significant role in the ability of particular economic classes to respond immediately to the disaster and to cope successfully with its aftermath. Their findings echo the perception and claims made in the popular press (ABC News 2005; Moore 2012). We study the more general impact of hurricane events on income distribution at the state level in the coastal United States based on historical data. In this way we create a basis for a more general and less ad hoc approach that addresses both policy and business aspects of the problem.

\section{Literature Review}

A large volume of literature focuses on natural disasters with an increased interest in hurricanes. Most of these studies are in areas of climate change, economic damage, social science, socioeconomics, emergency management, urban planning, and so on with a focus on specific geographies or hurricane events. While economic literature deals with income distribution in general, there are very few specific studies on how the overall state income distribution is affected by major hurricanes.

Masozera et al. (2007) found that preexisting socioeconomic conditions in New Orleans played a significant role in the ability of particular economic classes to respond to Hurricane Katrina and cope with it. Their analysis showed that Hurricane Katrina caused severe damage in all neighborhoods of New Orleans and that low-income people were not likely to be harder hit by the physical events but their lack of transportation and ability to recover faster made them the most disadvantaged.

A report published by Logan (2006) on the impact of Katrina suggests that the poor people suffered higher level of damage due to the fact that higher percentage of poor people lived in areas that sustained a higher level of damage. In the region as a whole, it was found that the disparities of damage were in line with the socioeconomic conditions. The most damaged areas had $45.8 \%$ of blacks, $20.9 \%$ of households with income below the poverty level, and $45.7 \%$ of homes were occupied by renters. In undamaged areas blacks represented $26.4 \%$ of population, $15.3 \%$ of people lived below the poverty level, and $30.9 \%$ of households were occupied by renters. Also smaller resources are available to poor and black people so they are less likely to return to their neighborhoods and rebuild.

Wealth and income effects of natural disasters were analyzed by Guimaraes et al. (1992) in case of Hurricane 
Hugo, which struck South Carolina in September 1989. Due to the infusion of billions of dollars from insurance and public assistance, some sectors of South Carolina's economy surged during the reconstruction period following Hurricane Hugo. Rebuilding efforts created a short-term boom before the economy returned to normal growth. The most benefited sectors included: construction, agriculture, agriculture and trade, retail trade, transportation, and public utilities.

Several studies on income distribution are using the Gini coefficient to measure income inequality but they focus on specific areas of the United States or a natural disaster (Brendler and Jones 1994; Madden 2000). For example, a study of income distribution effect in the case of Hurricane Katrina (Shaughnessy et al. 2010) identifies several theoretical models for modeling income distribution before and after the disaster. Their best fitted model can be used to estimate the Gini coefficient for the affected area as a measure of income inequality. Their findings indicate a decrease in income inequality from 0.5881(before Katrina) to 0.5776 (after Katrina) and 0.5604 (in 2007) in New Orleans in part due to an outflow of the poorest segment of the population from the affected area.

Our study differs from those above in the sense that we are using annual data on the Gini coefficient by state to estimate the economic impact of hurricanes on the overall state income distribution measured by the Gini coefficient. We aim to predict the degree of income inequality based on the intensity of hurricane economic damage and other economic and demographic variables. Although one could claim that it is difficult to separate wealth loss from income loss, there are many influential studies showing a strong positive correlation between wealth and permanent income (for example, Hall 1978), or a close connection between the consumption/income/wealth parallel (for example, Carroll and Summers 1991; Carroll 1997), thus justifying the use of income distribution in this study.

\section{Data}

This study uses a comprehensive panel of annual state level data for the period 1910-2005. Selected variables include Gini coefficient, gross domestic product (GDP), economic damages from past hurricanes, the proportion of nonwhite population, the proportion of population over age 60 , political control of the U.S. Senate, and the hurricane relief funds released by the federal government to the affected states. The states included in the study are the Atlantic Coast states and the Gulf of Mexico states, since they are generally considered the "hurricane" states. We recognize that more micro-level data such as county-level data would potentially be even more useful, but data for most variables pertinent for this research are not available at that level.
There are several competing measures of income inequality, such as the Gini coefficient, Theil entropy, and Pietra measures of inequality. McDonald and Jensen (1979) demonstrated that they all have advantages and disadvantages, but are highly correlated and thus can be used interchangeably. Hence the convenience of calculating the Gini coefficient played a major role in selecting it as a measure of income inequality in this research. Gini coefficient is defined as a measure of income inequality with a value closer to one indicating more inequality. It is calculated based on the Lorenz curve which is developed by plotting the cumulative portion of the population on the $x$-axis versus the cumulative portion of the total wealth/ income on the $y$-axis. The points on the curve show, for example, that $20 \%$ of all households may control $10 \%$ of the total income. In case of perfect income equality, every person is assumed to have the same income which is represented by a straight line, $y=x$, called "the line of perfect equality." Perfect inequality would be a case when one person has all the income and the rest has none. This represents "the line of perfect inequality" constructed for $y=0 \%$ when $x<100$ and $y=100 \%$ when $x=100 \%$. If we denote the area between observed Lorenz curve and "the line of perfect equality" as $Z_{1}$ and the area between observed Lorenz curve and "the line of perfect inequality" by $Z_{2}$, then the Gini coefficient is calculated as a ratio of $Z_{1} /\left(Z_{1}+Z_{2}\right)$ (Milanovic 1997). Data for the Gini coefficient by state and year for the period 1916-2005 are compiled by Frank (2008) based on the individual tax filing data available from the Internal Revenue Service. For more about the methodology by which the inequality measures were constructed, refer to Frank (2008).

Pielke et al. (2008) published data on estimated normalized economic damages in 2005 dollars related to hurricanes by year and state for the period 1900-2005. Economic damages are defined by Changnon (1996) as the direct losses associated with a hurricane's impact as determined in the weeks immediately after the hurricane's landfall. Normalization refers to a method of estimating the damages that would occur if a past hurricane made landfall under a different year's societal and economic conditions. The normalized economic damages are estimated using two different methods referred to as PL05 and CL05. The PL05 method proposed by Pielke and Landsea (1999) involves adjusting reported current year damages in dollars by inflation, real wealth per capita, and coastal county population growth. Collins and Lowe (2001) argued that in many coastal states the amount of property exposed to hurricanes has increased at a rate that exceeds local population growth because no effective planning limits were enforced on construction in the hurricane flood hazard zones. Thus the CL05 normalization method is proposed to account for an adjustment to the number of coastal county 
housing units rather than the population. In this method, the wealth adjustment accounts for the changes in housing units-wealth per housing unit—rather than per capita. We aggregated hurricane damages by year and state under the two methods. There were no data on hurricane damages available for the following coastal states: New Hampshire, New Jersey, Maryland, and Delaware in either of our sources as well as in the database of the National Hurricane Center (NHC). None of the sources explain this lack of data although it is clear that these states have been historically impacted by the hurricanes.

Additional demographic data include the proportion of people over age 60 and proportion of nonwhite population by year and state as published by the (U.S. Census Bureau 2013). These two variables are not included in the calculation of the Gini coefficient, but they do reflect important changes in the sociodemographic profile of the population of hurricane states since the 1960s. We also explored data on hurricane relief funds based on the government transfers reported by Congressional Research Service Report for Congress (CRS 2008). The values were adjusted to 2005 dollars but the data were limited to the years from 1989 to 2008. In order to measure economic growth by state over the same period we included historical data on state GDP as provided by the (United States Bureau of Economic Analysis 2013).

In the aftermath of hurricanes, it is not uncommon that the government is put in a position to make some ad hoc decisions about financial assistance provided to disaster areas. Political affiliation of the President and party controlling the Senate are not part of the calculation of the Gini coefficient and as such are included in this analysis. Popular perception is that a specific political affiliation (political parties) leads to differences in funding decisions. Data on the political affiliation (Democratic versus Republican) of the President, Senate, and House of Representatives were obtained from Senate (United States Senate 2013) and Congressional (United States House of Representatives 2013) websites to test that hypothesis.

\section{Methodology}

We develop a panel-data model that focuses on the hurricane states observed over the period 1910-2005. It is postulated that the outcome variable, the Gini coefficient, depends on explanatory variables such as hurricane damages, GDP; sociodemographic variables including proportion of nonwhite people; political dominance of the U.S. Senate; a set of cross-sectional dummy variables accounting for each of the study's hurricane states; and time trend. Other economic and sociodemographic variables such as government transfers to the affected states through the hurricane relief funds or the proportion of people aged 60 and above in total state population were also considered in initial modeling efforts, but were later eliminated from the model since they were not significant predictors of changes in income distribution.

Our model is a fixed-effects model.

$y=a l_{N T}+X \beta+Z_{\mu} \mu+v=Z \delta+Z_{\mu}+v$.

where $y$ is $N T \times 1, x$ is $N T \times K, Z=\left[l_{N T} X\right], \delta^{\prime}=\left(a^{\prime}, \beta^{\prime}\right)$, $l_{N T}$ is a vector of ones of dimension $N T$, and $v$ is a vector of stochastic disturbances independent and identically distributed $\operatorname{IID}\left(0, \sigma_{v}^{2}\right) . Z_{\mu}$ is the matrix of ones and zeroes, or individual dummies representing individual states. The reason to use a fixed-effects model instead of a simple pooled model utilizing ordinary least squares (OLS) is the possibility that omitted variables may lead to changes in the cross section. Fixed-effects model, that is, models with cross-sectional dummies only (such as in our model) or including both cross-sectional and time-series dummies, add dummy variables to allow for these changing intercepts (Pindyck and Rubinfeld 1998; Baltagi 1999). This procedure is meaningful only if both intercept and slope are not constant over cross-sectional units; if they are constant, more efficient parameter estimates can be obtained by combining all the data so that one large pooled regression is run with $N T$ observations. We have added $(N-1)$ dummy variables to the model and have omitted the remaining one, since their addition would result in perfect collinearity among the explanatory variables. The dummyvariable coefficients measure the change in the cross-section intercepts with respect to the omitted state (Alabama in our case). The decision to add dummy variables is also made on the basis of statistical testing. The test involves a comparison of the error sum of squares associated with the two estimation techniques. Since the OLS model includes more parameter restrictions than does the fixed-effects model (the intercepts are restricted to be equal over states), we would expect the error sum of squares to be higher for the OLS model. If the increase in the error sum of squares is not significant when the restrictions are added, we can conclude that the restrictions are proper, and OLS can be applied; otherwise, we choose the fixed-effects model. F-test statistics are used with the null hypothesis being that the equal-intercept restrictions are correct. Finally, it would be ideal to convert these data into natural logarithms in order to have the coefficients reported in the form of elasticity, but numerous zeroes in PL05 and CL05 prevent us from transforming the data.

\section{Discussion of the Results}

Econometric analysis was conducted in E-Views Version 6. A basic fixed-effects model measuring the impact of 
Table 1 Fixed-effect regression results for years 1916-2005

\begin{tabular}{|c|c|c|c|}
\hline Variable & Coefficient & SE & $p$-value \\
\hline Intercept & 0.433780 & 0.024658 & 0.0000 \\
\hline $\begin{array}{l}\text { Normalized } \\
\text { PL05 }\end{array}$ & $5.33 \mathrm{E}-13$ & $2.06 \mathrm{E}-13$ & 0.0099 \\
\hline Time & 0.000619 & 0.000531 & 0.2444 \\
\hline Connecticut & 0.035532 & 0.005190 & 0.0000 \\
\hline Florida & 0.045502 & 0.005260 & 0.0000 \\
\hline Georgia & 0.011788 & 0.005192 & 0.0234 \\
\hline Louisiana & 0.016826 & 0.005194 & 0.0012 \\
\hline Maine & 0.009033 & 0.005194 & 0.0823 \\
\hline Massachusetts & 0.025920 & 0.005197 & 0.0000 \\
\hline Mississippi & 0.016491 & 0.005196 & 0.0015 \\
\hline New York & 0.055246 & 0.005200 & 0.0000 \\
\hline North Carolina & 0.013456 & 0.005215 & 0.0100 \\
\hline Rhode Island & 0.021783 & 0.005205 & 0.0000 \\
\hline South Carolina & -0.010354 & 0.005205 & 0.0469 \\
\hline Texas & 0.026274 & 0.005211 & 0.0000 \\
\hline Virginia & -0.000410 & 0.005211 & 0.9373 \\
\hline \multicolumn{4}{|c|}{ Effects specifications } \\
\hline$R$-squared & 0.7216 & Akaike info criterion & -3.8497 \\
\hline Adj. $R$-squared & 0.7153 & Schwarz criterion & -3.7314 \\
\hline$F$-statistics & 113.9836 & $\begin{array}{l}\text { Hannan-Quinn } \\
\text { criterion }\end{array}$ & -3.8052 \\
\hline $\begin{array}{l}\text { Prob } \\
(F \text {-statistic })\end{array}$ & 0.0000 & Durbin-Watson stat. & 1.5268 \\
\hline \multicolumn{4}{|c|}{ Number of observations: 1,260} \\
\hline
\end{tabular}

aggregate damages (PL05 and CL05) on the Gini coefficient along with cross-sectional dummies, time trend, and the intercept was run for three distinct periods in order to check for the robustness of the relationship between hurricane damage and income distribution: 1916-2005 (Table 1), 1946-2005 (Table 2), and 1970-2005 (Table 3).

Results indicate the presence of a positive and statistically significant relationship between the PL05, CL05, and Gini coefficient in all three cases, which confirms the robustness (in a temporal sense) of this relationship. There were no statistically significant differences observed between the models containing CL05 relative to those with PL05. The best full-fledged model including economic, sociodemographic, and political variables has been estimated for the period 1970-2005. Lack of data available for some of the variables prevented us from estimating the fully specified model for any longer time period.

The best model (Table 3) was selected based on both minimized Akaike information criterion (AIC) and Schwarz criterion (SIC). Explanatory variables included in the best model are GDP, PL05, percent of nonwhite population, the political make-up of the U.S. Senate (Republican versus Democratic), time trend, state-dummies (with
Table 2 Fixed-effects regression results for years 1946-2005

\begin{tabular}{|c|c|c|c|}
\hline Variable & Coefficient & SE & $p$-value \\
\hline Intercept & 0.330764 & 0.027557 & 0.0000 \\
\hline $\begin{array}{l}\text { Normalized } \\
\text { PL05 }\end{array}$ & $5.25 \mathrm{E}-13$ & $1.52 \mathrm{E}-13$ & 0.0006 \\
\hline Time & 0.002602 & 0.000451 & 0.0000 \\
\hline Connecticut & 0.015426 & 0.002943 & 0.0000 \\
\hline Florida & 0.035755 & 0.002993 & 0.0000 \\
\hline Georgia & 0.010736 & 0.002944 & 0.0003 \\
\hline Louisiana & 0.016587 & 0.002959 & 0.0000 \\
\hline Maine & -0.011114 & 0.002947 & 0.0002 \\
\hline Massachusetts & 0.002189 & 0.002950 & 0.4582 \\
\hline Mississippi & 0.019765 & 0.002951 & 0.0000 \\
\hline New York & 0.025770 & 0.002955 & 0.0000 \\
\hline North Carolina & -0.002225 & 0.002971 & 0.4542 \\
\hline Rhode Island & -0.010046 & 0.002957 & 0.0007 \\
\hline South Carolina & -0.008737 & 0.002960 & 0.0033 \\
\hline Texas & 0.035314 & 0.002969 & 0.0000 \\
\hline Virginia & -0.003422 & 0.002966 & 0.2489 \\
\hline \multicolumn{4}{|c|}{ Effects specifications } \\
\hline$R$-squared & 0.9339 & Akaike info criterion & -5.3755 \\
\hline Adj. $R$-squared & 0.9317 & Schwarz criterion & -5.2121 \\
\hline$F$-statistics & 409.6627 & $\begin{array}{l}\text { Hannan-Quinn } \\
\text { criterion }\end{array}$ & -5.3129 \\
\hline $\begin{array}{l}\text { Prob } \\
(F \text {-statistic) }\end{array}$ & 0.0000 & Durbin-Watson stat. & 2.0768 \\
\hline \multicolumn{4}{|c|}{ Number of observations: 840} \\
\hline
\end{tabular}

Alabama serving as the base/omitted state), and the intercept. The cross-correlations among explanatory variables are all below 0.4 indicating that no multicollinearity problem exists. The difference between the coefficient of determination ( $R$-squared) and adjusted $R$-squared is very small, which suggests very good model specification (that is, no omitted or unnecessary variables in the model). The value of the $R$-squared of 0.93 indicates a very good fit of the data to the proposed model.

The value of the $F$-statistics indicates that we reject the null hypothesis of cross-sectional dummies being jointly equal to zero, that is, the fixed-effects model is superior to simple pooling and OLS estimation. Finally, the value of the Durbin-Watson statistic suggests that the model and the data do not suffer from the serial correlation problem, that is, the error terms from different time-series observations are not correlated.

The intercept value of 0.30 implies that the value of the Gini coefficient would be 0.30 assuming no impact of other variables on its value. Given that the Gini coefficient takes values between 0 and 1 , with higher number meaning there is more income inequality, the value of 0.30 means that "natural" or "autonomous" income inequality is relatively 
Table 3 Best fixed-effects regression model results for years 1970-2005

\begin{tabular}{|c|c|c|c|}
\hline Variable & Coefficient & SE & $p$ value \\
\hline Intercept & 0.304501 & 0.039826 & 0.0000 \\
\hline Time & 0.004580 & 0.000917 & 0.0000 \\
\hline GDP & $4.37 \mathrm{E}-14$ & $1.34 \mathrm{E}-14$ & 0.0012 \\
\hline $\begin{array}{l}\text { Normalized } \\
\text { PL05 }\end{array}$ & $5.38 \mathrm{E}-13$ & $1.60 \mathrm{E}-13$ & 0.0008 \\
\hline Nonwhite & 0.053968 & 0.023795 & 0.0238 \\
\hline Senate & 0.005485 & 0.002822 & 0.0525 \\
\hline Connecticut & 0.032399 & 0.004786 & 0.0000 \\
\hline Florida & 0.028139 & 0.005104 & 0.0000 \\
\hline Georgia & 0.004529 & 0.003681 & 0.2192 \\
\hline Louisiana & 0.018241 & 0.003795 & 0.0000 \\
\hline Maine & 0.000848 & 0.006492 & 0.8961 \\
\hline Massachusetts & 0.010375 & 0.006171 & 0.0934 \\
\hline Mississippi & 0.013516 & 0.004556 & 0.0032 \\
\hline New York & 0.006241 & 0.008487 & 0.4625 \\
\hline North Carolina & -0.013376 & 0.003952 & 0.0008 \\
\hline Rhode Island & 0.002358 & 0.004999 & 0.6517 \\
\hline South Carolina & -0.012311 & 0.003750 & 0.0011 \\
\hline Texas & 0.019528 & 0.006259 & 0.0019 \\
\hline Virginia & -0.010253 & 0.004113 & 0.0130 \\
\hline \multicolumn{4}{|c|}{ Effects specifications } \\
\hline$R$-squared & 0.9303 & Akaike info criterion & -5.4911 \\
\hline Adj. $R$-squared & 0.9257 & Schwarz criterion & -5.2230 \\
\hline$F$-statistics & 203.2495 & $\begin{array}{l}\text { Hannan-Quinn } \\
\text { criterion }\end{array}$ & -5.3856 \\
\hline $\begin{array}{l}\text { Prob } \\
(F \text {-statistic) }\end{array}$ & 0.0000 & Durbin-Watson stat. & 2.3973 \\
\hline
\end{tabular}

Number of observations: 504

low in the hurricane states of the United States. Indeed, that is expected and logical considering that economic, social, and political activities are geared towards changing (improving) the relative socioeconomic status of more influential interest groups compared to the rest of the population (Becker 1983) hence leading to an increase in the Gini coefficient. A positive time trend value suggests that there is an autonomous increase in income inequality over time with the Gini coefficient increasing by 0.004 per year.

The gross domestic product measures national income and output for a given country's economy. GDP is equal to the total expenditures for all final goods and services produced within the country in a stipulated period of time. GDP in the United States was worth USD 15,684.80 billion in 2012. If only the hurricane states included in this research are considered, their GDP in 2005 equaled USD 5,080 billion in 2005 , the last year included in the analysis. The prevailing paradigm in the economics literature is that with economic growth, as measured with an increase in GDP, there is an increase in economic inequality. That is, the poor become poorer in relative, and sometimes even in absolute, terms (Ravallion and Chen 1997; Fields 2003). Our result is consistent with that hypothesis, and the size of the estimated coefficient is within the boundaries of what one could expect. More specifically, an increase of annual GDP in our sample of hurricane states by USD 1,000 billion (or $20 \%$ of its 2005 value) would lead to an increase in the Gini coefficient of 0.043 or $4.3 \%$. If we are to reduce these numbers to values more likely to occur, a USD 100 billion or $2 \%$ increase in GDP would lead to an increase in Gini coefficient of $0.43 \%$. This means that a growth in national income leads to increase in inequality of income distribution albeit that response is relatively inelastic.

Our main interest is the impact of economic damage of catastrophic hurricane events on income distribution in hurricane states. An increase in normalized economic damages, PL05, by USD 100 billion would lead to an increase in the Gini coefficient of 0.054 or $5.4 \%$. For illustration purposes, normalized economic damages for the states under consideration in 2005 have been over USD 120 billion (Pielke et al. 2008) due to several damaging hurricanes that happened that year including Katrina, Wilma, Cindy, Rita, and Dennis. This result indicates that hurricane damages are the single most important factor impacting income distribution, that is, raising income inequality in hurricane states. While the sign of the coefficient was to some extent expected based on results of some of the case studies (for example, Logan 2006), the size of the coefficient is certainly very large. This has potentially important implications for both policy makers and the insurance industry. The sudden and irregular nature of these catastrophic events makes the impact of each individual event even more pronounced.

The only sociodemographic variable with significant impact on income distribution in our model is the percentage of nonwhite population in total population. As the nonwhite population increases by $1 \%$, the Gini coefficient increases by 0.054 or $5.4 \%$. Although this factor also has a large impact, the process of demographic change is gradual (unlike hurricane events) and could be planned for, predicted, and dealt with more easily by both policy makers and the insurance sector. Based on data from the (United States Bureau of Economic Analysis 2013), average salaries and per capita income are higher for white than nonwhite population. Hence, as the proportion of nonwhite population in the total population is expected to increase, this growth will lead to a further increase in income inequality as measured by the Gini coefficient and confirmed by our result.

The political party balance of the U.S. Senate also has important implications on the income distribution. Our 
results indicate that the Gini coefficient increases by 0.005 or $0.5 \%$ with a Democratic versus Republican Senate. At first this appears a bit counterintuitive given the common preconception of larger government (that is, more government taxing and spending) during Democratic control. Yet, that result is consistent with leading public choice and political economy models (for example, Ansolabehere and Snyder 2006). These models suggest that counties and states that traditionally give the highest vote share to the governing party receive larger shares of state and federal transfers to local and state governments. Hence although a Democrat-dominated government may increase spending relative to its Republican counterparts, these transfers do not necessarily go into the hands of the neediest segment of the population but rather are directed to the largest financial contributors and in turn exacerbate income inequality. When we explored data on hurricane relief funds based on the government transfers reported by Congressional Research Service Report for Congress, we found that the data are not a significant predictor of the income inequality and as such are not further considered in the analysis.

The cross-sectional dummies indicate in most cases the difference in intercepts across hurricane states relative to the omitted/base state of Alabama. However, the size of these coefficients is relatively small and vary from $0.032(3.2 \%)$ for Connecticut to -0.013 for North Carolina $(-1.3 \%)$ in the size of the Gini coefficient. This points to the socioeconomic, political, and demographic intricacies of individual states not captured by other variables in the model.

\section{Implications and Conclusions}

Several economic, political, and sociodemographic variables increase income inequality in U.S. Hurricane-exposed states. But the key finding in this article is that economic damage due to hurricane impacts further increases income inequality in the hurricane states of the United States. This is true both for the period from 1916 to 2005 and for several shorter subperiods. Economic damage is defined here as the direct losses associated with a hurricane's impact as determined in the weeks after the storm's landfall. This result has very important policy and insurance industry implications.

Both government and insurance industry consider hurricanes to be an "act of God." An "act of God" is a legal term for events outside human control, such as hurricanes, tornados, or other natural disasters for which no one can be held responsible (Black 1990). In the law of contracts, an act of God may be interpreted as an implied defense under the rule of impossibility or impracticability. If so, the promise is discharged because of unforeseen occurrences, which were unavoidable and would result in insurmountable delay, expense, or other material breach (Black 1990).
While individual and small-scale instances of damage due to natural disasters are typically not a government matter and are settled through contracts between insurance companies and their customers, large-scale catastrophic events such as hurricanes create damage that often exceeds the capacity of the insurance industry to handle without additional governmental involvement. The nature of events such as hurricanes is a raison d'être for the very existence of an insurance industry and yet one of the prime reasons for its potential downfall.

The problem arises when a relatively poor segment of the population inhabits high-exposure, high-risk areas of the coastal United States. Many low income people are unable to have their homes insured adequately (underinsured homes) or at all. Due to extremely high risk, insurance companies are likely to charge disproportionally high premiums in these areas. With every hurricane event, as our results confirm, there is a growing gap between wealthy and poor in these areas that further exacerbates the problem. Insurance companies can choose not to sell insurance to the relatively poor segment of population or can decide to charge very high premiums that cannot be afforded by the relatively poor portion of the population. But both strategies put government into peril since someone will, eventually, have to provide assistance to the victims of hurricane catastrophes.

In these situations, the insurance market itself is unlikely to be economically efficient. Most often a competitive market, without government intervention, is thought by economic theorists to be the most economically efficient system. An efficient market in this situation would imply that the relatively low income population will be priced out of the area by the insurance and construction industries. But in this case it seems that government intervention can increase the total welfare of consumers (home and business owners) and producers (the insurance industry as a service provider) in an otherwise competitive market. This is a fairly standard case of market failure, where prices fail to provide the proper signals to home owners and the insurance industry. Moreover, the sociodemographic consequences of a pure market mechanism are likely to be viewed as discriminatory in today's political climate. Hence it seems necessary that there must be some mechanism agreed upon by the government (for example, supplemental or base/minimum state insurance) and insurance industry that would establish certain thresholds. These basic agreements would have to establish two conditions. They must enable profitable business operations for insurance firms while not depleting state or federal budgets excessively in the aftermath of damage associated with hurricane events. At the same time any agreement would have to maintain demographic diversity in these hazardprone areas. 
Such an effort has recently materialized in the form of a law. Because private insurers rarely provide flood insurance, the program is run by the federal government, which kept premium rates artificially low in response to pressure from the real estate industry and other groups. Recent legislation, called the Homeowner Flood Insurance Affordability Act of 2014, amends the Biggert-Waters Flood Insurance Reform Act of 2012. The Biggert-Waters Act was supposed to gradually restore the national flood insurance program to solvency and encourage homeowners and communities to undertake flood mitigation efforts in high hazard areas. But it resulted in skyrocketing premiums for some property owners thus pricing them out of the coastal, hurricane-prone areas. This new legislation (United States Congress 2014) ensures that homes in flood-prone areas will no longer be subject to sharp increases in flood insurance premiums when properties are sold or when a new flood map places them in a higher-risk area. But people who live in older homes and enjoy subsidized flood insurance rates could still see annual increases in their premiums of up to $18 \%$. And all properties in high-risk areas will pay a new premium surcharge of either USD 25 or USD 250 per year to help offset the cost of the new bill. The bill, which was supported by the National Association of Realtors, is intended to help revive home sales in high-risk areas where uncertainty over flood insurance premiums was reducing transactions by targeting not only the more affluent portion of the population but also middle class American homeowners. While this action cannot be characterized as one that will lead to an improvement in inequality, it has the potential to prevent a further increase in income inequality.

Future research on this problem should focus on two areas: state level analysis using county level data (data availability permitting) and extending the data set to capture some most recent hurricane events such as Hurricane Sandy. More micro-level studies could potentially account for more intricacies and provide more information relevant for local/state policy makers and insurance businesses. Updating the existing data set is unlikely to change the (statistical) findings if considered in a 100 year time framework. But improvements in data quality would provide more confidence in the results of the study to potential users of the results outside academia.

Open Access This article is distributed under the terms of the Creative Commons Attribution License which permits any use, distribution, and reproduction in any medium, provided the original author(s) and the source are credited.

\section{References}

ABC News. 2005. Poorest hit hardest by Hurricane Katrina, 30 August 2005. http://abcnews.go.com/WNT/HurricaneKatrina/ story?id=1081329. Accesses 30 Dec 2012.
Annan, K. 1999. An increasing vulnerability to natural disasters. New York Times, 10 September 1999. http://www.nytimes.com/1999/ 09/10/opinion/10iht-edannan.2.t.html. Accessed 18 Sept 2014.

Ansolabehere, S., and J.M. Snyder Jr. 2006. Party control of state government and the distribution of public expenditures. The Scandinavian Journal of Economics 108(4): 547-569.

Baltagi, B.H. 1999. Econometric analysis of panel data. New York: Wiley.

Becker, G.S. 1983. A theory of competition among pressure groups for political influence. The Quarterly Journal of Economics 98(3): 371-400.

Black, H.C. 1990. Black's law dictionary, 6th edn. Saint Paul, MN: West Publishing.

Brendler, M., and C.A. Jones. 1994. Income distribution determinants within adjacent states: The case of louisiana and texas. Southwestern Economic Review 21(1): 71-79.

Carroll, C.D. 1997. Buffer-stock saving and the life cycle/permanent income hypothesis. The Quarterly Journal of Economics 112(1): $1-55$.

Carroll, C.D., and L.H. Summers. 1991. Consumption growth parallels income growth: Some new evidence. In National saving and economic performance, ed. B.D. Bernheim, and J.B. Shoven, 305-343. Chicago: The University of Chicago Press.

Changnon, S.A. 1996. The great flood of 1993: Causes, impacts and responses. Boulder, CO: Westview Press.

Collins, D.J., and S.P. Lowe. 2001. A macro validation dataset for U.S. hurricane model. Casualty Actuarial Society Forum, Casualty Actuarial Society, Arlington, VA. http://www.casact. org/pubs/forum/01wforum/01wf217.pdf. Accessed 18 Sept 2014.

CRS (Congressional Research Service). 2008. CRS report for congress. Emergency supplemental appropriations legislation for disaster assistance: Summary data (Updated 31 October 2008). http://assets.opencrs.com/rpts/RL33226_20081031.pdf. Accessed 31 Dec 2013.

Fields, G.S. 2003. Accounting for income inequality and its change: a new method, with application to the distribution of earnings in the United States. Research in Labor Economics 22: 1-38.

Frank, M.W. 2008. A new state-level panel of income inequality measures over the period 1916-2005. SHSU (Sam Houston State University) Economics and International Business Working Paper, No. SHSU_ECO_WP08-02.

Gronn, A. 1994. Capacity constraints and cycles in property-casualty insurance markets. The Rand Journal of Economics 25(1): 110-127.

Guimaraes, P., P.L. Hefner, and D.P. Woodward. 1992. Wealth and income effects of natural disasters: An econometric analysis of Hurricane Hugo. Working Paper: Division of Research, College of Business Administration, University of South Carolina.

Hall, R.E. 1978. Stochastic implications of the life cycle-permanent income hypothesis: Theory and evidence. Journal of Political Economy 86(6): 971-987.

Kahn, E.M. 2005. The death toll from natural disasters: The role of income, geography, and institutions. The Review of Economics and Statistics 87(2): 271-284.

Kellenberg, D.K., and A.M. Mobarak. 2008. Does rising income increase or decrease damage risk from natural disasters? Journal of Urban Economics 63(3): 788-802.

Logan, J.R. 2006. The impact of Katrina: Race and class in stormdamaged neighborhoods. S4, Special Structures in the Social Science, Hurricane Katrina Project. Providence, RI: Brown University. http://www.s4.brown.edu/Katrina/report.pdf. Accessed 27 Dec 2012.

Madden, J.F. 2000. Changes in income inequality within U.S. metropolitan areas. Kalamazoo, MI: W.E. Upjohn Institute for Employment Research.

Masozera, M., M. Bailey, and C. Kerchner. 2007. Distribution of impacts of natural disasters across income groups: A case study of New Orleans. Ecological Economics 63(2-3): 299-306. 
McDonald, J.B., and B.C. Jensen. 1979. An analysis of some properties of alternative measures of income inequality based on the gamma distribution function. Journal of the American Statistical Association 74(368): 856-860.

Milanovic, B. 1997. A simple way to calculate the Gini coefficient, and some implications. Economics Letters 56(1): 45-49.

Moore, A. 2012. Seven years after hurricane Katrina: Who owes whom? http://www.huffingtonpost.com/amanda-moore/katrinaanniversary_b_1841165.html. Accessed 11 Jan 2014.

Pielke Jr., R.A., and C.W. Landsea. 1999. La Niña, El Niño, and Atlantic hurricane damages in the United States. Bulletin of the American Meteorological Society 80(10): 2027-2033.

Pielke Jr., R.A., J. Gratz, C.W. Landsea, D. Collins, M.A. Saunders, and R. Musulin. 2008. Normalized hurricane damage in the United States: 1900-2005. Natural Hazards Review 9(1): 29-42.

Pindyck, R.S., and D.L. Rubinfeld. 1998. Econometric models and economic forecasts, 4th edn. Boston, MA: Irwin/McGraw-Hill.

Ravallion, M., and S. Chen. 1997. What can new survey data tell us about recent changes in distribution and poverty? The World Bank Economic Review 11(2): 357-382.

Shaughnessy, T.M., M.L. White, and M.D. Brendler. 2010. The income distribution effect of natural disasters: An analysis of Hurricane Katrina. Journal of Regional Analysis and Policy 40(1): 84-95.

Toya, H., and M. Skidmore. 2007. Economic development and the impacts of natural disasters. Economics Letters 94(1): 20-25.
United States Bureau of Economic Analysis. 2013. Regional data: GDP \& personal income. http://www.bea.gov/iTable/iTable.cfm?Re $\mathrm{qID}=70 \&$ step $=1 \#$ reqid=70\&step=7\&isuri $=1 \& 7001=1200 \& 7002=$ $1 \& 7003=200 \& 7090=70 \& 7005=1 \& 7006=01000 \& 7093=$ levels $\&$ 7004=sic. Last accessed 27 Dec 2013.

United States Census Bureau. 2013. Population estimates at state level. http://www.census.gov/popest/data/historical/index.html. Accessed 19 Nov 2013.

United States House of Representatives. 2013. http://www.house.gov/. Accessed 19 Nov 2013.

United States Senate. 2013. http://www.senate.gov/. Accessed 19 Nov 2013.

United States Congress. 2014. H.R. 3370-Homeowner flood insurance affordability act of 2014. Public Law No. 113-89. https://beta. congress.gov/bill/113th-congress/house-bill/3370. Accessed 18 Sept 2014.

Vellinga, P., and E. Mills. 2001. Insurance and other financial services. In Climate change 2001: Impacts, adaptation and vulnerability. Working Group II, Intergovernmental Panel on Climate Change, ed. J. McCarthy, O. Caniziani, N. Leary, D. Dokken, and K. White, 451-486. Cambridge, U.K: Cambridge University Press.

West, C.T., and D.G. Lenze. 1994. Modeling the regional impact of natural disaster and recovery: A general framework and an application to Hurricane Andrew. International Regional Science Review 17(2): 121-150. 